\title{
Determinants of Physical Activity during Early Childhood: A Systematic Review
}

\author{
Yao-Chuen Li1,2, Matthew Y. W. Kwan²,3, Sara King-Dowling1,2, John Cairney, ${ }^{1,2,3^{*}}$ \\ ${ }^{1}$ Department of Kinesiology, McMaster University, Hamilton, Canada \\ ${ }^{2}$ INfant and Child Health Lab, Department of Family Medicine, McMaster University, Hamilton, Canada \\ ${ }^{3}$ Department of Psychiatry and Behavioral Neurosciences and Offord Centre for Child Studies, McMaster \\ University, Hamilton, Canada \\ Email: ${ }^{*}$ cairnej@mcmaster.ca
}

Received 17 March 2015; accepted 7 May 2015; published 13 May 2015

Copyright (C) 2015 by authors and Scientific Research Publishing Inc.

This work is licensed under the Creative Commons Attribution International License (CC BY).

http://creativecommons.org/licenses/by/4.0/

(c) (i) Open Access

\begin{abstract}
Physical activity plays an important role for long-term health, and the preschool period is a vital developmental stage to establish healthy habits and behaviors. The purpose of this study was to conduct a systematic review of longitudinal studies examining the factors related to physical activity in young children. A literature search identifying physical activity studies in 2- to 6-year-old children was conducted in 2014. A total of 102 studies were initially identified, of which only nine met the inclusion criteria of prospective or longitudinal designs using objective measures of physical activity. Gender, aging, and seasonality (e.g. temperature, weather) were the three most common factors examined; followed by parental behaviors and weight status. Preschoolaged children are more physically active in better weather, and if parents, particularly fathers, spend more time playing with their children. Overall, few longitudinal studies have examined predictors of physical activity among young children. Of the limited evidence, it appears that the home environment may be a point for intervention, specifically encouraging parents to engage more with their young children in active pursuits. More longitudinal research is required to confirm and better understand salient factors related to physical activity during this critical early childhood period.
\end{abstract}

\section{Keywords}

Physical Activity, Preschooler, Environment, Accelerometry

\section{Introduction}

There are many established health benefits associated with regular participation in physical activity for children

${ }^{*}$ Corresponding author.

How to cite this paper: Li, Y. C., Kwan, M. Y. W., King-Dowling, S., \& Cairney, J. (2015). Determinants of Physical Activity during Early Childhood: A Systematic Review. Advances in Physical Education, 5, 116-127.

http://dx.doi.org/10.4236/ape.2015.52015 
(Camero, Hobbs, Stringer, Branscum, \& Taylor, 2012). Conversely, physical inactivity has been linked to negative health outcomes such as poor physical fitness and obesity, both of which places children at greater risk of cardiovascular disease, diabetes and metabolic syndrome later in life (Niederer et al., 2012; Sallis \& Owen, 1998; Wennberg, Gustafsson, Dunstan, Wennberg, \& Hammarström, 2013). Despite the many benefits, recent research suggests that preschool children spend very little time in active pursuits (L. Tremblay, Boudreau-Lariviere, \& Cimon-Lambert, 2012; Tucker, 2008). Physical activity during early childhood has been shown to track into adolescence and even into adulthood, making the early years a critical period for establishing physical activity behaviors (Goldfield, Harvey, Grattan, \& Adamo, 2012; Hinkley, Salmon, Okely, Hesketh, \& Crawford, 2012; Malina, 2001; McKenzie et al., 1997; Sigmund, De Ste Croix, Miklankova, \& Fromel, 2007; Skouteris et al., 2012; R. W. Taylor et al., 2009; W. C. Taylor, Blair, Cummings, Wun, \& Malina, 1999).

It is difficult to assess whether preschool children are engaging in physical activity to a level that confers positive health benefits; in part, because recommended guidelines vary by country and by age (Department of Health and Ageing, 2010; National Association for Sport and Physical Education, 2002; M. S. Tremblay et al., 2012; M. S. Tremblay et al., 2011; UK Department of Health, 2011). For example, Canadian guidelines recommend that children at 0 - 4 years of age should engage in 180 minutes of physical activity at any intensity spread throughout the day, and that children 5 and 6 years should engage in 60 minutes of daily moderate-to-vigorous physical activity (M. S. Tremblay et al., 2012; M. S. Tremblay et al., 2011). As a result, studies about compliance with physical activity guidelines tend to be variable, with results ranging from $84 \%$ of 3- to 4-year-old children being considered sufficiently active and $14 \%$ of 5 -year olds meeting the age-specific physical activity recommendations (Colley et al., 2013), to a more general finding of 54\% of preschoolers meeting the National Association for Sports and Physical Education guidelines of a minimum of 60 minutes of structured physical activity per day (Tucker, 2008). Meeting acceptable physical activity requirements appears to be a persistent issue among preschool-aged children, especially when intensity of activity is taken into consideration. It is therefore important that we understand the salient factors related to physical activity behaviors at an early age, and the potential targets for interventions to help young children engage in more physical activities.

Systematic reviews are an effective way to synthesize research findings, and to identify the level of evidence supporting knowledge claims and knowledge-gaps. Hinkley and colleagues (2008) conducted the first systematic review investigating the correlates of physical activity in 2- to 5-year-old children. Their study found gender, parental physical activity behaviors, and time spent outdoors as the strongest factors related to physical activity in preschool children (Hinkley, Crawford, Salmon, Okely, \& Hesketh, 2008). More recently, De Craemer and colleagues (2012) conducted another systematic review that included the examination of physical activity correlates in preschool-aged children, but did not find any strong evidence of any factor being related to young children's physical activity. Taken together, both reviews highlight the variability in the correlates being examined in the literature, and some inconsistencies in the findings. It should be noted, however, that most of the studies included in both of these comprehensive reviews are based on cross-sectional designs - which limit the ability to draw causal inferences. Furthermore, approximately half of the studies in both reviews used subjective measures of physical activity (14 of 24 in Hinkley et al. and 11 of 24 in De Craemer et al.). Subjective measures are less accurate at identifying the amount of time spent in the various intensities of physical activity in preschool children (Fairweather, Reilly, Grant, Whittaker, \& Paton, 1999; Jackson et al., 2003; Pfeiffer, McIver, Dowda, Almeida, \& Pate, 2006), and therefore combining results from studies using objective and subjective measures may be one reason for the lack of consistent findings in the literature. In order to better identify the predictors of physical activity in preschool children, the present study is a systematic review based on more specific and stringent inclusion criteria with studies that: 1) used a prospective or longitudinal design; and 2) used objective measures of physical activity.

\section{Methods}

\subsection{Search Procedure}

A two-step searching procedure was used to ensure complete identification of all studies that used a longitudinal design. In the first step, consistent with the search procedures outlined in Hinkley et al.'s (2008) systematic review and based on the system review guideline proposed by the PRISMA Group (Moher, Liberati, Tetzlaff, \& Altmane, 2010), published studies included in our review were initially retrieved from three sources. Computerized searches were conducted in the databases of PubMed, SPORTdiscus, CINAHL and PsycINFO, and using 
the following keywords: physical activity, determinant, correlate, and preschool(er). A study was included if it met the following inclusion criteria: 1) used a quantitative research design published in an English peer-review journal; 2) included a sample of young children between the ages of 2 and 6 years; 3) included any form of physical activity as the dependent variable; and 4) investigated the association between any biopsychosocial factor and physical activity. Two authors (YCL, SKD) independently conducted the initial search, examining titles and abstracts of identified studies. The reviewers subsequently compared studies identified to be potentially relevant for inclusion. A third author (JC) was consulted if consensus between the reviewers was not achieved. The primary search resulted in 94 articles that met the inclusion criteria. Reference checks, including targeted searches of all first authors, resulted in another eight studies identified for a total of 102 papers.

In the second step, studies for inclusion in our review were identified from the 102 articles if they met the following inclusion criteria: 1) used objective measures of physical activity (i.e., accelerometers, pedometers); and 2) used longitudinal or prospective study designs (defined as having one or more follow-up periods where physical activity was assessed at least twice during the early years when the children were between the ages of 2 and 6). This resulted in 17 longitudinal studies (17/102, 16.7\%) identified (Alderman, Benham-Deal, \& Jenkins, 2010; Arundell et al., 2013; Ball, Cleland, Timperio, Salmon, \& Crawford, 2009; Bürgi et al., 2011; Buss, Block, \& Block, 1980; Carver et al., 2011; Cleland et al., 2008; Gabel, Nguyen, Obeid, Proudfoot, \& Timmons, 2011; Gubbels et al., 2011; Jackson et al., 2003; Jago, Baranowski, Thompson, Baranowski, \& Greaves, 2005; McKee, Murtagh, Boreham, Nevill, \& Murphy, 2012; Saudino, 2012; Shen, Alexander, Milberger, \& Jen, 2013; R. W. Taylor et al., 2009; R. W. Taylor, Williams, Farmer, \& Taylor, 2013; Telford, Finch, Barnett, Abbott, \& Salmon, 2012). Seven of these studies (7/17, 41\%) were excluded because they had included follow-up periods beyond the age of 6 and did not report changes within the preschool-aged period (Alderman et al., 2010; Arundell et al., 2013; Ball et al., 2009; Carver et al., 2011; Cleland et al., 2008; Gubbels et al., 2011; Telford et al., 2012). Ten of the studies (59\%) met the inclusion criteria (Bürgi et al., 2011; Buss et al., 1980; Gabel et al., 2011; Jackson et al., 2003; Jago et al., 2005; McKee et al., 2012; Saudino, 2012; Shen et al., 2013; R. W. Taylor et al., 2009; R. W. Taylor et al., 2013); however, two published papers reporting on the same study sample (presenting results of their 2- and 4-year follow-ups) were included in this initial collection of papers (R. W. Taylor et al., 2009; R. W. Taylor et al., 2013). So the results of these papers were included as a single study. Therefore, a total of nine studies were included for analysis (see Figure 1 for complete breakdown).

\subsection{Study Quality}

In order to assess bias and to evaluate the quality of the studies included in this review, we used a 10-item checklist, which is specifically modified for prospective studies, spanning four domains: study attrition and follow-up duration, assessment of determinants, assessment of outcome measures, and data analyses (Uijtdewilligen et al., 2011). Two authors (YCL and SKD) independently reviewed all included studies. A third author (JC) was consulted if both raters failed to reach a consensus. A score of " 1 " was given if the study met the specificcriterion in each domain. If multiple determinants or correlates were measured, the score was calculated by dividing the number of reliable/valid tools by the total number of tools used. A score of 0 indicated that the study failed to meet the criterion, and a question mark (?) indicated that the criterion was either unknown or not mentioned in the manuscript. The quality score is presented as the percentage of the sum of all ten item scores assessed, with higher scores indicating higher study quality. Using the cutoff point suggested, a score of $<70 \%$ was considered low quality (Uijtdewilligen et al., 2011).

\section{Results and Discussion}

\subsection{Characteristics of Studies Retrieved}

Of the nine longitudinal studies identified by our search, eight studies were conducted between 2003 and 2013, while one study was published prior to 2000. Six of the nine studies (67\%) were identified as high quality (two scoring 70\% (Buss et al., 1980; Jackson et al., 2003), one scoring 80\% (Shen et al., 2013) and three scoring 90\% (Jago et al., 2005; Saudino, 2012; R. W. Taylor et al., 2013), while three studies (33\%) were of low quality (scoring below 70\% (Bürgi et al., 2011; Gabel et al., 2011; McKee et al., 2012); see Table 1). The reason for a low quality assessment was primarily due to low response rates $(<80 \%)$, and the lack of follow-up participation $(<80 \%)$ or reporting insufficient information to calculate follow-up rates. 


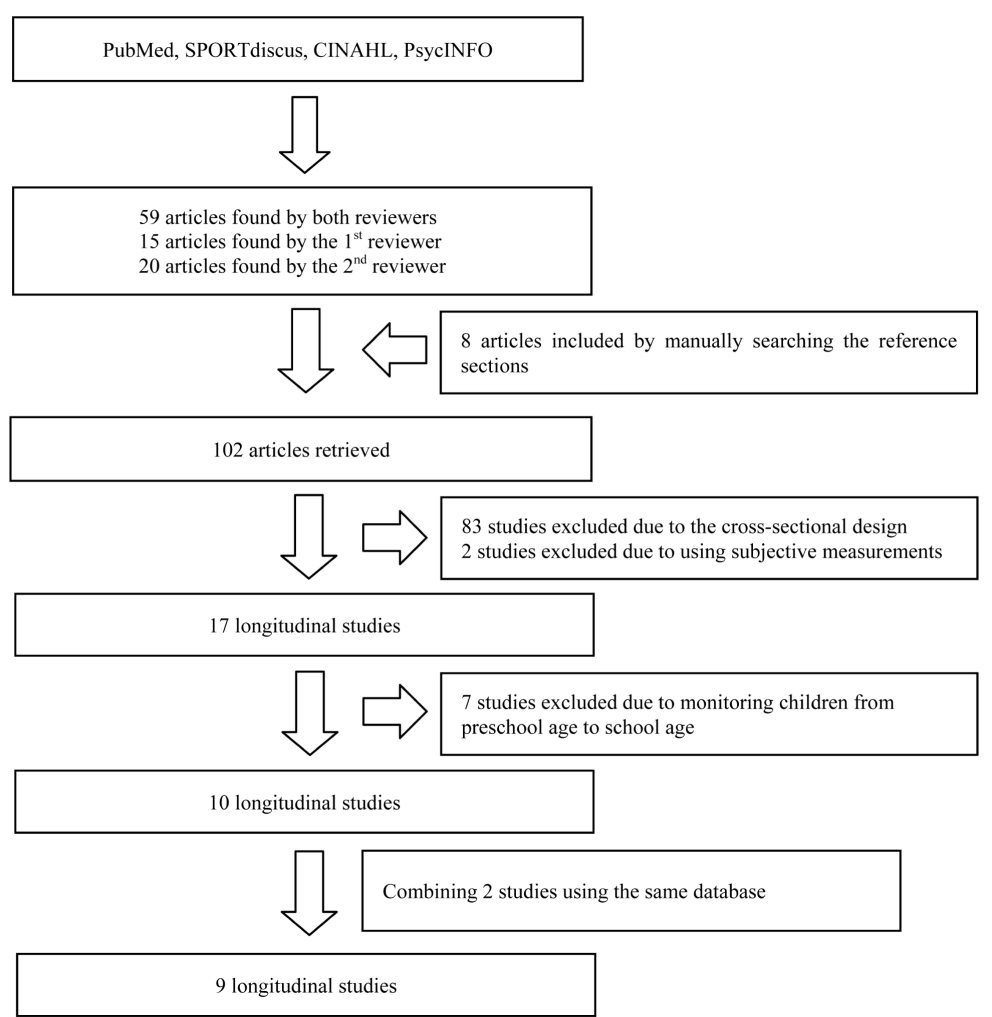

Figure 1. Searching procedure and the result of article retrieved.

Table 1. Quality of studies included in the current review.

\begin{tabular}{|c|c|c|c|c|c|c|c|c|c|}
\hline Quality criteria $^{\mathbf{a}}$ & $\begin{array}{l}\text { Buss et al. } \\
\text { (1980) }\end{array}$ & $\begin{array}{l}\text { Bürgi et } \\
\text { al. (2011) }\end{array}$ & $\begin{array}{l}\text { Gabel et } \\
\text { al. (2011) }\end{array}$ & $\begin{array}{c}\text { Jago et al. } \\
(2005)\end{array}$ & $\begin{array}{c}\text { Jackson } \\
\text { et al. } \\
\text { (2003) }\end{array}$ & $\begin{array}{l}\text { McKee et } \\
\text { al. (2012) }\end{array}$ & $\begin{array}{l}\text { Saudino } \\
\text { (2012) }\end{array}$ & $\begin{array}{l}\text { Shen et } \\
\text { al. (2013) }\end{array}$ & $\begin{array}{l}\text { Taylor et } \\
\text { al. (2009, } \\
2013)^{\mathbf{b}}\end{array}$ \\
\hline
\end{tabular}

\section{Study attrition and}

follow-up duration

A. Participation rate at baseline $\geq 80 \%$

B. Response at follow-up $\geq 80 \%$

C. Follow-up at least one year

Assessment of determinants

D. Determinants measured with a reliable tool

E. Determinants measured with a valid tool

$?$
$?$
1

$\begin{array}{llllllll}0 & ? & ? & ? & 0 & ? & 1 & 0 \\ ? & 0 & 1 & 0 & 0 & 1 & 1 & 1 \\ 0 & 1 & 1 & 1 & 1 & 1 & 0 & 1\end{array}$

Assessment of outcome measure

F. Physical activity measured with a reliable tool

G. Physical activity measured with a valid tool

\section{Data analyses}

H. Results presented with SD, CI or SE

I. Controlled for confounding

J. Sample size $\geq 10$ times number of independent variables

$\begin{array}{ccccccccc}1 & 1 & 1 & 1 & 1 & 0.66 & 1 & 1 & 1 \\ 1 & 0.5 & 1 & 1 & 1 & 0.66 & 1 & 1 & 1\end{array}$

\section{Quality score (\%)}

(1)

${ }^{\mathrm{a}}$ Rating of criteria: 1 = meeting the criterion, 0 = not meeting the criterion, ? = unknown, ${ }^{\mathrm{b}}$ The score for each item was the average of both studies, ${ }^{\mathrm{c}}$ The percentage of the positive scores. 
In terms of physical activity assessment, six studies used accelerometers (Bürgi et al., 2011; Gabel et al., 2011; Jackson et al., 2003; Saudino, 2012; Shen et al., 2013; R. W. Taylor et al., 2013), one used pedometers (McKee et al., 2012), one used the actometer (Buss et al., 1980), and one used heart rate telemetry (Jago et al., 2005). Sample size for the studies ranged from 17 to 314, with only three studies having fewer than 100 participants (Gabel et al., 2011; McKee et al., 2012; Shen et al., 2013). On average, the studies followed participants over an 18-month period, but two had a follow-up period of less than 12 months (Bürgi et al., 2010; Shen et al., 2013). The research came from several geographic areas, including Europe $(n=4$, 44.4\%) (Bürgi et al., 2011; Jackson et al., 2003; Jago et al., 2005; McKee et al., 2012), North America (n=4, 44.4\%) (Buss et al., 1980; Gabel et al., 2011; Saudino, 2012; Shen et al., 2013), and the Pacific region $(n=1,11.1 \%)(R . W$. Taylor et al., 2013). A complete summary of the included studies is presented in Table 2.

\subsection{Main Findings}

Across the nine studies examined, there were a total of 19 variables that were examined in relation to physical activity in young children. The five most common variables examined across studies were aging (Bürgi et al., 2011; Gabel et al., 2011; Jackson et al., 2003; Jago et al., 2005; McKee et al., 2012; Saudino, 2012; Shen et al., 2013; R. W. Taylor et al., 2013), gender (Bürgi et al., 2011; Buss et al., 1980; Jackson et al., 2003; Jago et al., 2005; McKee et al., 2012; Saudino, 2012; Shen et al., 2013; R. W. Taylor et al., 2013), seasonality (McKee et al., 2012; Shen et al., 2013; R. W. Taylor et al., 2013), parental behaviors (Jago et al., 2005; McKee et al., 2012; R. W. Taylor et al., 2009), and weight status (Bürgi et al., 2011; Jackson et al., 2003).

\subsubsection{Physical Activity over Time}

Given that we restricted the search to only prospective or longitudinal studies, most studies examined the changes in physical activity over time. Specifically, eight studies examined the changes in physical activity behaviors during early childhood (i.e., aging effect). Four of the studies (two high quality and two low quality) found a positive relationship (Bürgi et al., 2011; Jackson et al., 2003; McKee et al., 2012; Saudino, 2012), suggesting that children became more active as they get older. Two other high quality studies found a negative association between aging and physical activity in young children (Jago et al., 2005; R. W. Taylor et al., 2013), showing physical activity decreasing over time. There were two studies (one high quality and one low quality) that did not find a significant relationship (Gabel et al., 2011; Shen et al., 2013). The study by Buss and colleagues (1980) monitored physical activity over one year using actometers. However, the levels of physical activity (e.g., time or counts) were not reported, whereby only the correlations of physical activity between two time points were included, which hindered our ability to appropriately assess the changes in physical activity over time. Overall, the evidence appears to be mixed in terms of how physical activity changes over time, as these young children became older.

Comparatively, our findings are different than previous reviews of preschool children which have identified no clear association between age and physical activity (De Craemer et al., 2012; Hinkley et al., 2008), although we believe the evidence does not appear to be strong enough to draw clear conclusions. Children are generally considered to be the most active segment of the population, whereby physical activity tends to decrease as children enter adolescences and into early adulthood_(Ross \& Pate, 1987; Sallis, 1993). Our findings suggest that more work is needed to better understand the patterns of physical activity behaviors across the early childhood period, including assessment tools capturing various forms of physical activity (e.g., organized sports, free-play activities) on multiple occasions during this formative period. This is of particular importance, given the increased emphasis on active play rather than structured or organized activity among children, as a way to increase overall physical activity among youth (Brockman, Jago, \& Fox, 2010; Canadian Society for Exercise Physiology, 2013).

\subsubsection{Gender and Physical Activity}

There were a total of eight studies that examined the effect of gender on physical activity, but the evidence regarding the association between gender and physical activity in young children was inconsistent. Overall, there were four studies (three of which were high quality) that found boys to be more active over time than girls (Bürgi et al., 2011; Jackson et al., 2003; Saudino, 2012; R. W. Taylor et al., 2013), and four studies (three that were high quality) that found no differences in physical activity between genders (Buss et al., 1980; Jago et al., 2005; McKee et al., 2012; Shen et al., 2013). Although the remaining one study by Gabel and colleagues (2011) 
Table 2. Summary of the studies retrieved and main findings.

\begin{tabular}{|c|c|c|c|c|c|}
\hline $\begin{array}{l}\text { Authors \& } \\
\text { Country }\end{array}$ & Study Design & Sample & PA Measure & $\begin{array}{l}\text { Outcome } \\
\text { Measure }\end{array}$ & Findings \\
\hline $\begin{array}{l}\text { Buss et al. } \\
\text { (1980) } \\
\text { US }\end{array}$ & $\begin{array}{l}\text { 1-year longitudinal } \\
\text { study examining } \\
\text { the relationship } \\
\text { between early } \\
\text { activity level and } \\
\text { personality } \\
\text { characteristics }\end{array}$ & $\begin{array}{c}1233 \text { yr children } \\
\text { (50\% boys) }\end{array}$ & $\begin{array}{c}\text { Actometer ( } 2 \text { h } \\
\text { per session, } 3-4 \\
\text { sessions with an } \\
\text { interval of } 1 \text { week) }\end{array}$ & $\begin{array}{l}\text { Sex, IQ, and } \\
\text { personality using } \\
\text { the California } \\
\text { Child Q Set }\end{array}$ & $\begin{array}{l}\text { The sex difference was inconsistent; boys were } \\
\text { significantly more active than girls at age } 4 \text {, but } \\
\text { not at age } 3 \text {. } \\
\text { PA was not related to IQ across ages. } \\
\text { Preschool activity level was only related to a set of } \\
\text { interpersonal and motoric attributes. }\end{array}$ \\
\hline $\begin{array}{l}\text { Bürgi et al. } \\
\text { (2011) } \\
\text { CH }\end{array}$ & $\begin{array}{l}\text { 9-month } \\
\text { longitudinal study } \\
\text { investigating the } \\
\text { relationship of PA } \\
\text { with motor skills, } \\
\text { aerobic fitness and } \\
\text { body fat }\end{array}$ & $\begin{array}{l}2174-6 \text { yr } \\
\text { children }(48 \% \\
\text { boys, mean } \\
\text { age }=5.2 \mathrm{yr})\end{array}$ & $\begin{array}{l}\text { Accelerometer: } \\
10.8 \mathrm{~h} / \mathrm{d} \text { (at least } \\
2 \text { weekdays \& } 1 \\
\text { weekend day with } \\
\text { at least } 6 \mathrm{~h} / \mathrm{d})\end{array}$ & $\begin{array}{l}\text { Agility: obstacle } \\
\text { course } \\
\text { Balance: balance } \\
\quad \text { beam } \\
\text { Aerobic fitness: } \\
\text { 20-m shuttle run } \\
\text { \% body fat: BIA }\end{array}$ & $\begin{array}{l}\text { PA was positively associated with motor skills and } \\
\text { aerobic fitness at baseline as well as with the } \\
\text { longitudinal changes. Specifically, only VPA was } \\
\text { related to changes in aerobic fitness. Higher PA } \\
\text { was associated with less \%body fat at baseline, } \\
\text { but not with its change. } \\
\text { Conversely, baseline motor skills, aerobic fitness or } \\
\text { \%body fat were not related to changes in PA. }\end{array}$ \\
\hline $\begin{array}{l}\text { Gabel et al. } \\
\text { (2011) } \\
\text { CA }\end{array}$ & $\begin{array}{l}\text { 15-month } \\
\text { longitudinal study } \\
\text { investigating the } \\
\text { tracking of PA }\end{array}$ & $\begin{array}{l}173 \text { - } 5 \text { yr children } \\
\text { (59\% boys, mean } \\
\text { age }=4.4 \text { yr, mean } \\
\text { BMI = } 16.6 \text {, } \\
\text { 23.5\% overweight) }\end{array}$ & $\begin{array}{l}\text { Accelerometer: } \\
10.6 \mathrm{hr} / \mathrm{d} \text { in ear } 1 \\
\text { and } 11.6 \mathrm{hr} / \mathrm{d} \text { in } \\
\text { year } 2 \text { (at least } 5 \\
\mathrm{hr} / \mathrm{d}, 4 \text { days } \\
\text { including at } \\
\text { least } 1 \\
\text { weekend day) }\end{array}$ & Age & $\begin{array}{l}\text { Total PA was not significantly different between } \\
\text { year } 1 \text { and } 2 \text {. } \\
\text { MVPA significantly increased at year } 2 \text {. }\end{array}$ \\
\hline $\begin{array}{l}\text { Jago et al. } \\
\text { (2005) } \\
\text { UK }\end{array}$ & $\begin{array}{l}\text { 3-year longitudinal } \\
\text { study examining } \\
\text { the relationship } \\
\text { between PA } \\
\text { and sedentary } \\
\text { behaviors }\end{array}$ & $\begin{array}{c}1493 \text { - } 4 \text { yr } \\
\text { children (49\% } \\
\text { boys, mean age = } \\
\text { 4.4yr, mean BMI = } \\
\text { 15.5, 37\% African } \\
\text { American, 37\% } \\
\text { Anglo-American, } \\
\text { 26\% Hispanic) }\end{array}$ & $\begin{array}{l}\text { Heart rate monitor } \\
\text { (from } 7 \text { am to } 7 \\
\text { pm with at least } \\
504 \text { min/d, } \\
\text { HR }>140 \text { bpm } \\
\text { as MVPA) } \\
\text { Observation using } \\
\text { the Child's } \\
\text { Activity } \\
\text { Rating Scale }\end{array}$ & $\begin{array}{l}\text { Sex, sedentary } \\
\text { behaviors (TV } \\
\text { viewing and not } \\
\text { TV viewing), and } \\
\text { parental } \\
\text { encouragement } \\
\text { or discouragement } \\
\text { for PA }\end{array}$ & $\begin{array}{l}\text { Gender was not a significant predictor. } \\
\text { Sedentary behaviors, excluding TV viewing, } \\
\text { significantly predicted heart-rate monitored PA. } \\
\text { Parental encouragement or discouragement was } \\
\text { not a significant predictor of PA. }\end{array}$ \\
\hline $\begin{array}{l}\text { Jackson et } \\
\text { al. (2003) } \\
\text { UK }\end{array}$ & $\begin{array}{l}\text { 1-year longitudinal } \\
\text { study describing } \\
\text { normal } \\
\text { developmental } \\
\text { changes in PA }\end{array}$ & $\begin{array}{l}1043 \text { - 4yr } \\
\text { children (50\% } \\
\text { boys, mean age = } \\
\text { 3.7yr, only } 60 \\
\text { children } \\
\text { re-assessed after } \\
\text { one year) }\end{array}$ & $\begin{array}{l}\text { Accelerometer: } \\
10.7 \mathrm{hr} / \mathrm{d} \text { for } 4.1 \\
\text { days (at least } 6 \\
\text { hr/d, } 3 \text { days } \\
\text { including } 2 \text { week } \\
\quad \text { days and } 1 \\
\text { weekend day) }\end{array}$ & $\begin{array}{l}\text { Sex, age, SES, } \\
\text { and week } \\
\text { days/weekend }\end{array}$ & $\begin{array}{l}\text { At baseline, boys were significantly more active } \\
\text { than girls. } \\
\text { Children's PA significantly increased after } 1 \text { year. } \\
\text { There were not significant differences in activity } \\
\text { level associated with SES and between weekday } \\
\text { and weekend. } \\
\text { BMI was weakly associated with PA. }\end{array}$ \\
\hline $\begin{array}{l}\text { McKee et } \\
\text { al. (2012) } \\
\text { UK }\end{array}$ & $\begin{array}{l}\text { 1-year longitudinal } \\
\text { study examining } \\
\text { the influence of } \\
\text { season and } \\
\text { increasing age on } \\
\text { objectively } \\
\text { assessed PA and } \\
\text { the stability of } \\
\text { young children's } \\
\text { PA ranking }\end{array}$ & $\begin{array}{l}853 \text { - } 4 \text { yr } \\
\text { children (61\% } \\
\text { boys, only } 37 \\
\text { children } \\
\text { re-assessed after } \\
\text { about one year) }\end{array}$ & $\begin{array}{l}\text { Pedometer: at least } \\
3 \text { weekdays \& } 1 \\
\text { weekend day with } \\
\text { at least } 9 \text { h/d) }\end{array}$ & $\begin{array}{l}\text { Seasonal variable } \\
\text { (spring and } \\
\text { winter), parental } \\
\text { duration of daily } \\
\text { play with child, } \\
\text { neighborhood } \\
\text { safety, and the } \\
\text { amount of time } \\
\text { children spent } \\
\text { outdoors }\end{array}$ & $\begin{array}{l}\text { There was no evidence to support a gender } \\
\text { difference in the PA levels. } \\
\text { There was a substantive difference in the children's } \\
\text { PA between winter and spring. } \\
\text { The duration of fathers' daily play with children } \\
\text { was related to winter PA, whereas having a safe } \\
\text { place to play was related to spring PA. } \\
\text { There is a main effect for year of measurement in } \\
\text { weekly, weekday, and weekend PA (PA are greater } \\
\text { at the age of 5). }\end{array}$ \\
\hline
\end{tabular}




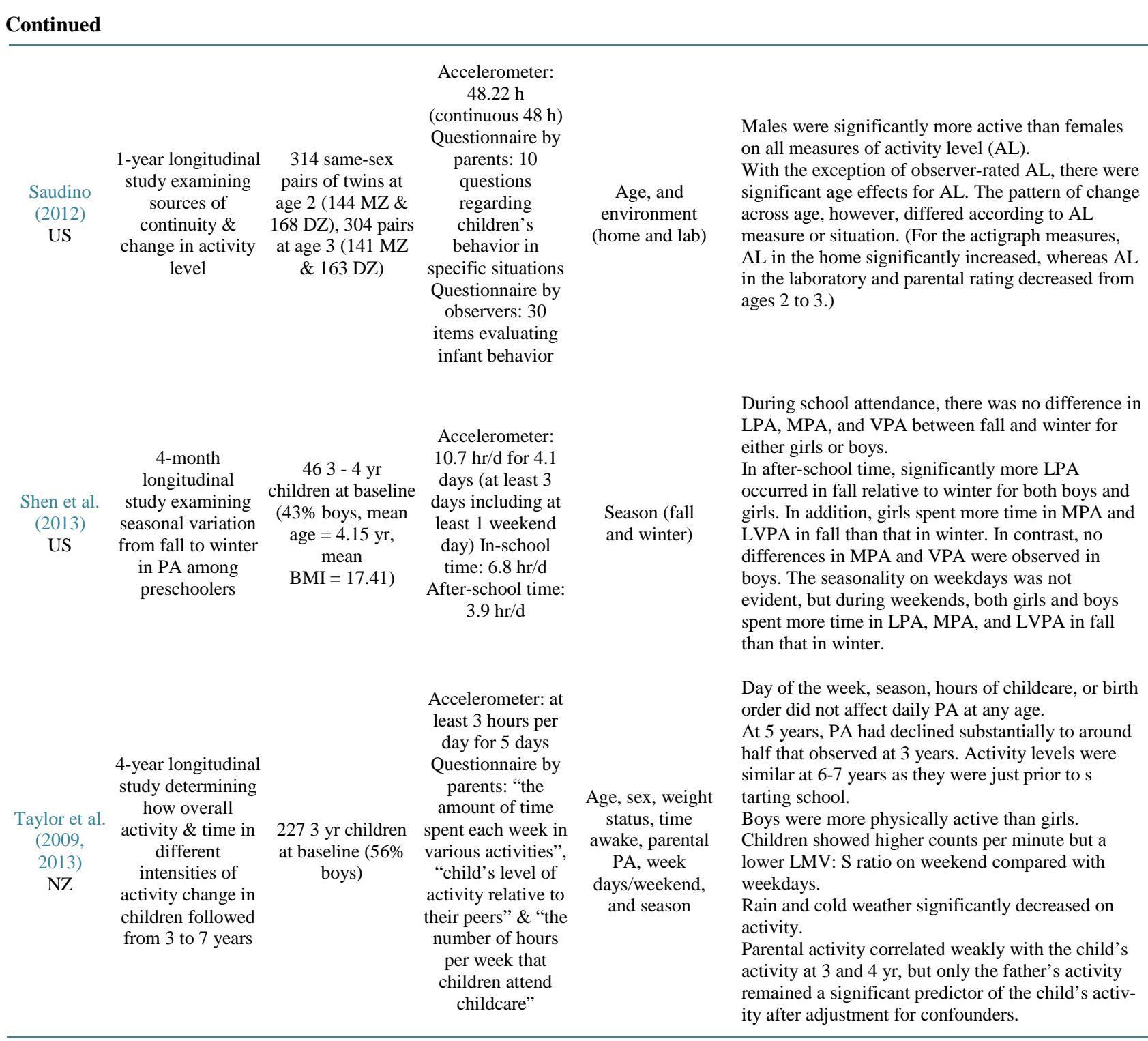

also recruited both boys $(\mathrm{n}=10)$ and girls $(\mathrm{n}=7)$ and tracked physical activity over one year, this study did not compare the difference in physical activity between boys and girls, and this makes it impossible to examine the gender effect.

Our findings from the current review are inconsistent with Hinkley and colleagues (2008) and the broader literature, which shows a robust and consistent gender effect: young boys being more active than girls throughout childhood and into adolescence (Bauman et al., 2012; Hinkley et al., 2008; Sallis, Prochaska, \& Taylor, 2000). Rather, our findings are consistent with the review by De Craemer and colleagues (2008), indicative of no clear gender effect on overall physical activity. It is posited that gender differences during childhood occur because boys begin to confront greater pressure from their peers to join organized sports when they begin school (Cairney, Hay, Faught, Mandigo, \& Flouris, 2005), while girls are encouraged to participate in quieter activities (Rose, Larkin, \& Berger, 1997). During the preschool years, however, boys and girls may not be influenced to the same degree by these socially constructed roles (Cairney et al., 2005; Ismael \& Lawson, 2012; Nicaise, Kahan, \& Sallis, 2011; Rose et al., 1997). Consistent with this reasoning, the unequivocal gender differences in the physical activity literature may not be evident until later in childhood, when children begin primary school. Given the limited longitudinal evidence, there is an obvious need for more rigorous studies to concretely show how gender influences physical activity during early childhood, and potentially how this changes over time. 


\subsubsection{Seasonal Effects and Weather Conditions}

Three studies (two high quality and one low quality) investigated the effect of seasonality and/or weather. While previous systematic reviews conclude that no relationship between physical activity and different seasons or weather conditions, results of the current review suggest that preschool children tend to be more physically active during warmer seasons or in better weather (McKee et al., 2012; Shen et al., 2013; R. W. Taylor et al., 2013). For example, the study by Shen and colleagues (2013) found young children spend more after-school time in light physical activity and more time in total physical activity during weekends in the fall season compared to the winter. Similarly, McKee et al. (2012) reported children accruing close to 2000 more steps in the spring than winter. Taylor and colleagues (2013) concluded that an increase in one mm of rainfall and a decrease in temperature by one degree Celsius equated to a $2 \%$ decrease in physical activity participation. Overall, these findings are consistent with some recent cross-sectional studies showing shorter hours of daylight and lower daily temperature during cooler seasons negatively impact physical activity in young children (Lovasi et al., 2011; McKee et al., 2012). While promising, it is important to acknowledge that only a limited number of longitudinal studies have investigated seasonal and/or weather effects on physical activity in preschool children, and more research is needed to better understand how temperature, season, and other related factors such as daylight and climate change impact physical activity behaviors. Despite the limitations, findings from the current review suggest that intervention efforts should focus on facilitating greater physical activity behaviors for children during the colder seasons, or when the weather is less than ideal for engagement in outdoor activities.

\subsubsection{Parental Behaviors}

Previous systematic reviews had inconsistent findings in regard to the relationships between parental behaviors and physical activity in preschool children. While Hinkley and colleagues (2008) suggests that role modeling and direct parental involvement are associated with increased physical activity in young children, De Craemer and colleagues (2012) did not find support for parental modeling and involvement nor other parental behaviors (e.g. parenting style, parental encouragement or enjoyment) in their review. Results from two of three studies in the current review examining this relationship (one high quality and one low quality) found parental physical activity and time spent playing with children to be significant factors related to young children's physical activity (McKee et al., 2012; R. W. Taylor et al., 2009). Specifically, preschool-aged children engage in more physical activity if their parents, in particular fathers, participate in more physical activity and spend more time playing with them (McKee et al., 2012; R. W. Taylor et al., 2009). Beets \& Foley (2008) conducted a similar cross-sectional study and found paternal time spent with children being both directly and indirectly related to their child's participation in physical activity. Another study has found the frequency of a father's walking being positively associated with their children's outdoor play (Spurrier, Magarey, Golley, Curnow, \& Sawyer, 2008). More research, however, is required to improve our understanding of how paternal and maternal behaviors, and family structures (e.g., dual parent family, single parent family, etc.) impact physical activity in young children. Similarly, it may also be important to understand how parental influences interact with other environmental factors such as weather, climate, and season, as these could have a potential moderating effect.

\subsubsection{Weight Status}

Weight status, characterized by either percentage body fat or body mass index (BMI), was examined in two studies (one high quality and one low quality) (Bürgi et al., 2011; Jackson et al., 2003). Consistent with the broader literature, including previous reviews (Hinkley et al., 2008; Sallis et al., 2000; Uijtdewilligen et al., 2011), these studies found weight status to be unrelated or weakly associated to physical activity in preschool children. Overall, weight status appears to be more strongly related to sedentary behaviors (e.g. TV viewing or gaming) rather than physical activity (Cox et al., 2012; Kimbro, Brooks-Gunn, \& McLanahan, 2011; Uijtdewilligen et al., 2011). The small sample size, however, severely limits the conclusions that can be drawn - though obesity is important factor that should not be discounted, particularly as the rate of obesity among young children continues to rise (Canning, Courage, \& Frizzell, 2004; Colley et al., 2013).

\subsection{Study Limitations}

While this was the first systematic review to examine determinants of physical activity among preschool-aged children over time, there are several limitations that need to be acknowledged. First, the review highlights the 
very limited number of prospective or longitudinal physical activity studies using objective measures of physical activity among preschool-aged children. The current systematic review added another six studies to the three studies previously included by the Hinkley et al. (2008) review. Despite an overall increase in the number of these studies, the number of longitudinal studies is still very limited. Second, although we reviewed prospective or longitudinal studies, many included only one assessment of the factors related to physical activity over time. This assumes, for example, that these determinants are stable: which may not be the case for factors such as parental physical activity behaviors which may fluctuate, or for the weather corresponding to the physical activity assessment period. In order to better understand the factors related to physical activity during early childhood, future research must repeatedly assess potentially time-varying (e.g., weather; parental behaviors) determinants of physical activity in children. Third, most of the included studies were drawn from a convenience sample, which raises questions concerning generalizability and sample bias. Finally, none of the studies included in the current review explicitly state a theoretical framework that the determinants examined were based upon. More longitudinal research grounded in theory is needed to begin to understand the salient factors predicting physical activity in young children.

\subsection{Future Directions}

Overall, there is a clear need for more longitudinal research using objective assessments of children's physical activity among the preschool-age population. The limited evidence thus far suggests that parental behaviors and season/weather were environmental contextual factors that appear to be important for physical activity in young children. Future research must continue to investigate these environmental contextual factors to confirm the conclusions drawn from the current review. Furthermore, studies need to explore other environmental factors that may be influencing their day-to-day physical activities. For example, some preschool-aged children attend day care centers, while others are primarily exposed to the home environment. It is important to consider the structure of care and how that may influence opportunities for physical activity during this early developmental period. Importantly, these studies may begin to demonstrate how it influences changes in physical activity over time, providing insight towards maintenance of sustained participation in physical activity as young children transition into mid- and later childhood. Similarly, it is important to understand how the interactions between social and environmental factors impact behaviors. For instance, it may be possible that some parents use active transport (e.g., walking, biking) to bring children to care centers, or that greater social interactions with peers in these settings through active play may be positively influencing their physical activity behaviors. No studies to date have examined how these interacting biopsychosocial factors influence young children's physical activity.

\section{Conclusion}

This systematic review retrieved longitudinal studies using objective measures of physical activity to examine determinants of physical activity in preschool-aged children. Overall, environmental context such as parental behaviors and weather/season appear to be factors that impact young children's physical activity behaviors. However, as the limited number of studies included in the current review, these findings must be interpreted with caution. Overall, in order to better inform various points for interventions, more theory- or model-based prospective research is required to establish the salient determinants of physical activity behaviors among preschool children.

\section{Acknowledgements}

JC is supported by an endowed professorship in child health research through the Department of Family Medicine at McMaster University.

\section{References}

Alderman, B. L., Benham-Deal, T. B., \& Jenkins, J. M. (2010). Change in Parental Influence on Children’s Physical Activity over Time. Journal of Physical Activity \& Health, 7, 60-67.

Arundell, L., Ridgers, N. D., Veitch, J., Salmon, J., Hinkley, T., \& Timperio, A. (2013). 5-Year Changes in after School Physical Activity and Sedentary Behavior. American Journal of Preventive Medicine, 44, 605-611.

http://dx.doi.org/10.1016/j.amepre.2013.01.029 
Ball, K., Cleland, V. J., Timperio, A. F., Salmon, J., \& Crawford, D. A. (2009). Socioeconomic Position and Children’s Physical Activity and Sedentary Behaviors: Longitudinal Findings from the CLAN Study. Journal of Physical Activity \& Health, 6, 289-298.

Bauman, A. E., Reis, R. S., Sallis, J. F., Wells, J. C., Loos, R. J., \& Martin, B. W. (2012). Correlates of Physical Activity: Why Are Some People Physically Active and Others Not? Lancet, 380, 258-271. http://dx.doi.org/10.1016/S0140-6736(12)60735-1

Beets, M. W., \& Foley, J. T. (2008). Association of Father Involvement and Neighborhood Quality with Kindergartners' Physical Activity: A Multilevel Structural Equation Model. American Journal of Health Promotion, 22, 195-203. http://dx.doi.org/10.4278/ajhp.22.3.195

Brockman, R., Jago, R., \& Fox, K. R. (2010). The Contribution of Active Play to the Physical Activity of Primary School Children. Preventive Medicine, 51, 144-147. http://dx.doi.org/10.1016/j.ypmed.2010.05.012

Bürgi, F., Meyer, U., Granacher, U., Schindler, C., Marques-Vidal, P., Kriemler, S., \& Puder, J. J. (2011). Relationship of Physical Activity with Motor Skills, Aerobic Fitness and Body Fat in Preschool Children: A Cross-Sectional and Longitudinal Study (Ballabeina). International Journal of Obesity, 35, 937-944. http://dx.doi.org/10.1038/ijo.2011.54

Bürgi, F., Meyer, U., Niederer, I., Ebenegger, V., Marques-Vidal, P., Granacher, U., \& Puder, J. J. (2010). Socio-Cultural Determinants of Adiposity and Physical Activity in Preschool Children: A Crosssectional Study. BMC Public Health, 10, 733. http://dx.doi.org/10.1186/1471-2458-10-733

Buss, D. M., Block, J. H., \& Block, J. (1980). Preschool Activity Level: Personality Correlates and Developmental Implications. Child Development, 51, 401-408. http://dx.doi.org/10.2307/1129273

Cairney, J., Hay, J., Faught, B. E., Mandigo, J., \& Flouris, A. (2005). Developmental Coordination Disorder, Self-Efficacy toward Physical Activity, and Play: Does Gender Matter? Adapted Physical Activity Quarterly, 22, 67-82.

Camero, M., Hobbs, C., Stringer, M., Branscum, P., \& Taylor, L. (2012). A Review of Physical Activity Interventions on Determinants of Mental Health in Children and Adolescents. International Journal of Mental Health Promotion, 14, 196206. http://dx.doi.org/10.1080/14623730.2012.752901

Canadian Society for Exercise Physiology (2013). Canadian Physical Activity and Canadian Sedentary Behaviour Guidelines. Ottawa: Canadian Society for Exercise Physiology.

Canning, P. M., Courage, M. L., \& Frizzell, L. M. (2004). Prevalence of Overweight and Obesity in a Provincial Population of Canadian Preschool Children. Canadian Medical Association Journal, 171, 240-242. http://dx.doi.org/10.1503/cmaj.1040075

Carver, A., Timperio, A. F., Hesketh, K. D., Ridgers, N. D., Salmon, J. L., \& Crawford, D. A. (2011). How Is Active Transport Associated with Children's and Adolescents' Physical Activity over Time? International Journal of Behavioral Nutrition \& Physical Activity, 8, 1-126. http://dx.doi.org/10.1186/1479-5868-8-126

Cleland, V., Crawford, D., Baur, L. A., Hume, C., Timperio, A., \& Salmon, J. (2008). A Prospective Examination of Children's Time Spent Outdoors, Objectively Measured Physical Activity and Overweight. International Journal of Obesity, 32, 1685-1693. http://dx.doi.org/10.1038/ijo.2008.171

Colley, R. C., Garriguet, D., Adamo, K. B., Carson, V., Janssen, I., Timmons, B. W., \& Tremblay, M. S. (2013). Physical Activity and Sedentary Behavior during the Early Years in Canada: A Cross-Sectional Study. International Journal of Behavioral Nutrition \& Physical Activity, 10, 54. http://dx.doi.org/10.1186/1479-5868-10-54

Cox, R., Skouteris, H., Rutherford, L., Fuller-Tyszkiewicz, M., Dell’Aquila, D., \& Hardy, L. L. (2012). Television Viewing, Television Content, Food Intake, Physical Activity and Body Mass Index: A Cross-Sectional Study of Preschool Children Aged 2 - 6 Years. Health Promotion Journal of Australia, 23, 58-62.

De Craemer, M., De Decker1, E., De Bourdeaudhuij, I., Vereecken, C., Deforche, B., Manios, Y., \& Cardon, G. (2012). Correlates of Energy Balance-Related Behaviours in Preschool Children: A Systematic Review. Obesity Reviews, 13, 1328. http://dx.doi.org/10.1111/j.1467-789X.2011.00941.x

Department of Health and Ageing (2010). National Physical Activity Guidelines for Australians. Physical Activity Recommendations for 0-5 Year Olds. Canberra: Government of Australia.

Fairweather, S. C., Reilly, J. J., Grant, S., Whittaker, A., \& Paton, J. Y. (1999). Using the CSA Activity Monitor in Pre-School Children. Pediatric Exercise Science, 11, 414-421.

Gabel, L., Nguyen, T., Obeid, J., Proudfoot, N. A., \& Timmons, B. W. (2011). Short-Term Muscle Power and Speed in Preschoolers Exhibit Stronger Tracking than Physical Activity. Applied Physiology, Nutrition, and Metabolism, 36, 939-945. http://dx.doi.org/10.1139/h11-118

Goldfield, G. S., Harvey, A., Grattan, K., \& Adamo, K. B. (2012). Physical Activity Promotion in the Preschool Years: A Critical Period to Intervene. International Journal of Environmental Research \& Public Health, 9, 1326-1342. http://dx.doi.org/10.3390/ijerph9041326

Gubbels, J. S., Kremers, S. P., Stafleu, A., de Vries, S. I., Goldbohm, R. A., Dagnelie, P. C., \& Thijs, C. (2011). Association 
between Parenting Practices and Children’s Dietary Intake, Activity Behavior and Development of Body Mass Index: The KOALA Birth Cohort Study. International Journal of Behavioral Nutrition \& Physical Activity, 14, 18. http://dx.doi.org/10.1186/1479-5868-8-18

Hinkley, T., Crawford, D., Salmon, J., Okely, A. D., \& Hesketh, K. (2008). Preschool Children and Physical Activity: A Review of Correlates. American Journal of Preventive Medicine, 34, 435-441. http://dx.doi.org/10.1016/j.amepre.2008.02.001

Hinkley, T., Salmon, J., Okely, A. D., Hesketh, K., \& Crawford, D. (2012). Correlates of Preschool Children’s Physical Activity. American Journal of Preventive Medicine, 43, 159-167. http://dx.doi.org/10.1016/j.amepre.2012.04.020

Ismael, N. T., \& Lawson, L. M. (2012). The Impact of Preschoolers' Gender and Sensory Preferences on Physical Activity Levels during Play. The British Journal of Occupational Therapy, 75, 429-435. http://dx.doi.org/10.4276/030802212X13470263980874

Jackson, D. M., Reilly, J. J., Kelly, L. A., Montgomery, C., Grant, S., \& Paton, J. Y. (2003). Objectively Measured Physical Activity in a Representative Sample of 3- to 4-Year-Old Children. Obesity Research, 11, 420-425. http://dx.doi.org/10.1038/oby.2003.57

Jago, R., Baranowski, T., Thompson, D., Baranowski, J., \& Greaves, K. A. (2005). Sedentary Behavior, Not TV Viewing, Predicts Physical Activity among 3- to 7-Year-Old Children. Pediatric Exercise Science, 17, 364-376.

Kimbro, R. T., Brooks-Gunn, J., \& McLanahan, S. (2011). Young Children in Urban Areas: Links among Neighborhood Characteristics, Weight Status, Outdoor Play, and Television Watching. Social Science \& Medicine, 72, 668-676. http://dx.doi.org/10.1016/j.socscimed.2010.12.015

Lovasi, G. S., Jacobson, J. S., Quinn, J. W., Neckerman, K. M., Ashby-Thompson, M. N., \& Rundle, A. (2011). Is the Environment near Home and School Associated with Physical Activity and Adiposity of Urban Preschool Children? Journal of Urban Health, 88, 1143-1157. http://dx.doi.org/10.1007/s11524-011-9604-3

Malina, R. (2001). Physical Activity and Fitness: Pathways from Childhood to Adulthood. American Journal of Human Biology, 13, 162-172. http://dx.doi.org/10.1002/1520-6300(200102/03)13:2<162::AID-AJHB1025>3.0.CO;2-T

McKee, D. P., Murtagh, E. M., Boreham, C. A., Nevill, A. M., \& Murphy, M. H. (2012). Seasonal and Annual Variation in Young Children’s Physical Activity. Medicine \& Science in Sports \& Exercise, 44, 1318-1324. http://dx.doi.org/10.1249/MSS.0b013e3182464db5

McKenzie, T. L., Sallis, J. F., Elder, J. P., Berry, C. C., Hoy, P. L., Nader, P. R., Zive, M. M., \& Broyles, S. L. (1997). Physical Activity Levels and Prompts in Young Children at Recess: A Two-Year Study of a Bi-Ethnic Sample. Research Quarterly for Exercise \& Sport, 68, 195-202. http://dx.doi.org/10.1080/02701367.1997.10607998

Moher, D., Liberati, A., Tetzlaff, J., \& Altmane, D. G., PRISMA Group (2010). Preferred Reporting Items for Systematic Reviews and Meta-Analyses: The PRISMA Statement. International Journal of Surgery, 8, 336-341. http://dx.doi.org/10.1016/j.ijsu.2010.02.007

National Association for Sport and Physical Education (2002). Active Start: A Statement of Physical Activity Guidelines for Children Birth to 5 Years. Oxon Hill, MD: AAHPERD Publications.

Nicaise, V., Kahan, D., \& Sallis, J. F. (2011). Correlates of Moderate-to-Vigorous Physical Activity among Preschoolers during Unstructured Outdoor Play Periods. Preventive Medicine, 53, 309-315. http://dx.doi.org/10.1016/j.ypmed.2011.08.018

Niederer, I., Kriemler, S., Zahner, L., Burgi, F., Ebenegger, V., Marques-Vidal, P., \& Puder, J. J. (2012). BMI Group-Related Differences in Physical Fitness and Physical Activity in Preschool-Age Children: A Cross-Sectional Analysis. Research Quarterly for Exercise \& Sport, 83, 12-19. http://dx.doi.org/10.1080/02701367.2012.10599820

Pfeiffer, K. A., McIver, K. L., Dowda, M., Almeida, M. J., \& Pate, R. R. (2006). Validation and Calibration of the Actical Accelerometer in Preschool Children. Medicine \& Science in Sports \& Exercise, 38, 152-157. http://dx.doi.org/10.1249/01.mss.0000183219.44127.e7

Rose, B., Larkin, D., \& Berger, B. G. (1997). Coordination and Gender Influences on the Perceived Competence of Children. Adapted Physical Activity Quarterly, 14, 210-221.

Ross, J. G., \& Pate, R. R. (1987). The National Children and Youth Fitness Study. II. A Summary of Findings. Journal of Physical Education, Recreation \& Dance, 58, 51-56. http://dx.doi.org/10.1080/07303084.1987.10604374

Sallis, J. F. (1993). Epidemiology of Physical Activity and Fitness in Children and Adolescents. Critical Reviews in Food Science and Nutrition, 33, 403-408. http://dx.doi.org/10.1080/10408399309527639

Sallis, J. F., \& Owen, N. (1998). Physical Activity and Behavioral Medicine. Thousand Oaks, CA: SAGE.

Sallis, J. F., Prochaska, J. J., \& Taylor, W. C. (2000). A Review of Correlates of Physical Activity of Children and Adolescents. Medicine \& Science in Sports \& Exercise, 32, 963-975. http://dx.doi.org/10.1097/00005768-200005000-00014

Saudino, K. J. (2012). Sources of Continuity and Change in Activity Level in Early Childhood. Child Development, 83, 266- 
281. http://dx.doi.org/10.1111/j.1467-8624.2011.01680.x

Shen, B., Alexander, G., Milberger, S., \& Jen, K. L. (2013). An Exploratory Study of Seasonality and Preschoolers’ Physical Activity Engagement. Journal of Physical Activity \& Health, 10, 993-999.

Sigmund, E., De Ste Croix, M., Miklankova, L., \& Fromel, K. (2007). Physical Activity Patterns of Kindergarten Children in Comparison to Teenagers and Young Adults. European Journal of Public Health, 17, 646-651. http://dx.doi.org/10.1093/eurpub/ckm033

Skouteris, H., Dell’Aquila, D., Baur, L. A., Dwyer, G. M., McCabe, M. P., Ricciardelli, L. A., \& Fuller-Tyszkiewicz, M. (2012). Physical Activity Guidelines for Preschoolers: A Call for Research to Inform Public Health Policy. The Medical Journal of Australia, 196, 174-177. http://dx.doi.org/10.5694/mja11.11015

Spurrier, N. J., Magarey, A. A., Golley, R., Curnow, F., \& Sawyer, M. G. (2008). Relationships between the Home Environment and Physical Activity and Dietary Patterns of Preschool Children: A Cross-Sectional Study. International Journal of Behavioral Nutrition \& Physical Activity, 30, 31. http://dx.doi.org/10.1186/1479-5868-5-31

Taylor, R. W., Murdoch, L., Carter, P., Gerrard, D. F., Williams, S. M., \& Taylor, B. J. (2009). Longitudinal Study of Physical Activity and Inactivity in Preschoolers: The FLAME Study. Medicine \& Science in Sports \& Exercise, 41, 96-102. http://dx.doi.org/10.1249/MSS.0b013e3181849d81

Taylor, R. W., Williams, S. M., Farmer, V. L., \& Taylor, B. J. (2013). Changes in Physical Activity over Time in Young Children: A Longitudinal Study Using Accelerometers. PLoS ONE, 25, e81567. http://dx.doi.org/10.1371/journal.pone.0081567

Taylor, W. C., Blair, S. N., Cummings, S. S., Wun, C. C., \& Malina, R. M. (1999). Childhood and Adolescent Physical Activity Patterns and Adult Physical Activity. Medicine \& Science in Sports \& Exercise, 31, 118-123. http://dx.doi.org/10.1097/00005768-199901000-00019

Telford, A., Finch, C. F., Barnett, L., Abbott, G., \& Salmon, J. (2012). Do Parents' and Children’s Concerns about Sports Safety and Injury Risk Relate to How Much Physical Activity Children Do? British Journal of Sports Medicine, 46, 10841088. http://dx.doi.org/10.1136/bjsports-2011-090904

Tremblay, L., Boudreau-Lariviere, C., \& Cimon-Lambert, K. (2012). Promoting Physical Activity in Preschoolers: A Review of the Guidelines, Barriers, and Facilitators for Implementation of Policies and Practices. Canadian Psychology, 53, 280-290. http://dx.doi.org/10.1037/a0030210

Tremblay, M. S., LeBlanc, A. G., Carson, V., Choquette, L., Gorber, S. C., Dillman, C. et al. (2012). Canadian Physical Activity Guidelines for the Early Years (Aged 0 - 4 Years). Applied Physiology, Nutrition, \& Metabolism, 37, 345-356. http://dx.doi.org/10.1139/h2012-018

Tremblay, M. S., Warburton, D. E., Janssen, I., Paterson, D. H., Latimer, A. E., Rhodes, R. E. et al. (2011). New Canadian Physical Activity Guidelines. Applied Physiology, Nutrition, \& Metabolism, 36, 36-46. http://dx.doi.org/10.1139/H11-009

Tucker, P. (2008). The Physical Activity Levels of Preschool-Aged Children: A Systematic Review. Early Childhood Research Quarterly, 23, 547-558. http://dx.doi.org/10.1016/j.ecresq.2008.08.005

Uijtdewilligen, L., Nauta, J., Singh, A. S., van Mechelen, W., Twisk, J. W. R., van der Horst, K., \& Chinapaw, M. J. M. (2011). Determinants of Physical Activity and Sedentary Behaviour in Young People: A Review and Quality Synthesis of Prospective Studies. British Journal of Sports Medicine, 45, 896-905. http://dx.doi.org/10.1136/bjsports-2011-090197

UK Department of Health (2011). Start Active, Stay Active: A Report on Physical Activity from the Four Home Countries' Chief Medical Officers.

http://www.dh.gov.uk/en/Publicationsandstatistics/Publications/PublicationsPolicyAndGuidance/DH_128209

Wennberg, P., Gustafsson, P. E., Dunstan, D. W., Wennberg, M., \& Hammarström, A. (2013). Television Viewing and Low Leisure-Time Physical Activity in Adolescence Independently Predict the Metabolic Syndrome in Mid-Adulthood. Diabetes Care, 36, 2090-2097. http://dx.doi.org/10.2337/dc12-1948 